\title{
¿REPRESENTACIÓN CORPORATIVA EN LAS SOMBRAS? UNA REFLEXIÓN HISTÓRICA SOBRE LAS TENDENCIAS POLÍTICAS DEL PRESENTE
}

\author{
Sofía Correa Sutil
}


SOFÍA CORREA SUTIL

Historiadora de la Pontificia Universidad Católica de Chile y Ph. D. en la Universidad de Oxford. Académica de la Facultad de Derecho de la Universidad de Chile. 


\section{¿REPRESENTACIÓN CORPORATIVA EN LAS SOMBRAS? \\ UNA REFLEXIÓN HISTÓRICA SOBRE LAS TENDENCIAS POLÍTICAS DEL PRESENTE}

A mediados de este año 2011 se han producido en Santiago y en las principales ciudades del país enormes manifestaciones, con una convocatoria tan numerosa -se han calculado incluso cien mil personas en una de las que se ha llevado a cabo para defender la educación pública- como no se las veía desde aquellos tiempos épicos en los cuales la ciudadanía se movilizaba segura de que podría derrotar a la dictadura en las urnas. La significativa diferencia con aquellos tiempos es que las actuales expresiones masivas no han sido lideradas por los partidos políticos, con la excepción relativa del Partido Comunista. A lo más, algunos de sus dirigentes, buscando no quedarse fuera del impulso social, se han sumado a ellas desde una segunda línea.

Por otra parte, en este contexto de ausencia de los partidos en el liderazgo de las movilizaciones estudiantiles y de las protestas sociales, hemos tenido conocimiento de las últimas encuestas sobre percepciones políticas, las cuales muestran una y otra vez el rechazo ciudadano a la gestión de todos los partidos, así como también a las instituciones centrales del régimen democrático, es decir, el Congreso Nacional y la Presidencia de la República, además de los Tribunales de Justicia. Las cifras son dramáticas: los niveles de rechazo de la ciudadanía superan el $60 \%$ cuando se pregunta por la evaluación de las alianzas políticas, ya sea del Gobierno o de oposición, y también cuando se pregunta por la gestión del Senado y de la Cámara de Diputados. La confianza en estas instituciones es ínfima: menos del 20\% de los chilenos confían en ellas, incluso los encuestados manifiestan mayor confianza en asociaciones intermedias, como los sindicatos y las organizaciones empresariales, que por los partidos políticos, el Congreso o el Poder Judicial.

No es necesario ser muy perceptivo para darse cuenta de que el país visualiza en todos los sectores del espectro político a dirigencias partidistas encapsuladas, ajenas a los anhelos y frustraciones de las mayorías ciudadanas, a la vez que cercanas en sus gustos, apreciaciones y criterios; a los sectores más ricos del país que gozan de un desvergonzado consumo lujoso y superfluo, publicitado además por los medios masivos de comunicación social. Es cierto que el problema es compartido a nivel internacional: los jóvenes "indignados" de la Puerta del Sol en Madrid tampoco quieren saber nada de sus dirigentes políticos. Pero no por eso es menos grave o específico, y puede tener en Chile un impacto inesperado.

Por de pronto, en nuestro país la desafección de la ciudadanía para con sus representantes se ha agravado con el sistema electoral que tenemos, puesto que el sistema binominal creado durante la dictadura y vigente hasta el presente, ha tenido el efecto de que sean las cúpulas de los partidos las que deciden de antemano los resultados electorales. Son ellas las que designan, sin consultar a las bases, quiénes serán los dos candidatos a los cupos parlamentarios que lleva cada alianza partidista, y como la mayor probabilidad es que se elija a uno de cada una de las dos combinaciones políticas 
en disputa, la competencia por los votos se da más bien entre los dos candidatos de la misma lista. Incluso ha sucedido que las cúpulas de los partidos deciden proteger a determinadas figuras y asegurar su elección a como de lugar. El caso más extremo fue cuando el acuerdo partidista transversal aseguró las senadurías de Eduardo Frei RuizTagle y de Andrés Allamand por Valdivia, al llevarlos como candidatos únicos de cada lista, evitando así la competencia electoral con algún otro candidato de sus mismas filas, e impidiendo por tanto que la elección misma pudiese tener influencia alguna en el resultado final. No debería sorprender que el primero no alcanzara la reelección presidencial pocos años más tarde. Por ello, con muy pocas excepciones (solo un senador por Magallanes que es independiente), el sistema binominal ha impedido que la ciudadanía pueda pedir cuentas a sus representantes ante el Congreso, y premiarlos o castigarlos en cada elección. En realidad, es a su propio partido ante el cual responde cada parlamentario a la hora de definir su futuro político.

A esta nefasta debilidad representativa, que se puede percibir desde hace décadas, se agregó en 2005, por iniciativa del Presidente Ricardo Lagos, una reforma al sistema electoral, de rango constitucional, es decir, ampliamente respaldada en el Congreso, mediante la cual se entregó a las dirigencias de los partidos políticos la decisión de designar a la persona que debería reemplazar al parlamentario que, por renuncia o muerte, dejara vacío su cargo. Antes de esta reforma, la Constitución del 80 disponía que el parlamentario saliente debiera ser reemplazado por su compañero de lista de la elección que lo llevó al Congreso, disposición que operó cuando el senador Jaime Guzmán fue asesinado. En cambio, la primera ocasión en que se aplicó la reforma de 2005 fue cuando la Presidenta Bachelet nombró en un ministerio a una diputada en ejercicio, y el Partido Socialista designó a su reemplazante, una figura que nunca se había jugado su porvenir político en una disputa electoral. Desde entonces, en un año y medio del actual gobierno de Sebastián Piñera, se ha recurrido ya cuatro veces a la misma práctica de nombrar como ministros a parlamentarios en ejercicio, y han sido sus partidos quienes, por disposición legal, designan a sus reemplazantes ${ }^{1}$. Al parecer, la paciencia ciudadana se ha colmado, y lo ha hecho saber; las dirigencias partidistas no han tenido más que hacerse cargo de la indignación, y han comenzado a pensar en una nueva reforma. Falta por hacer notar que durante el gobierno de Lagos el Congreso actuó como buzón receptor de las iniciativas presidenciales, sin tomar distancia alguna para examinar la inconveniencia de propuestas como esta.

Lo antedicho nos lleva a hacer notar que la desconfianza de la ciudadanía en los partidos políticos y en las instituciones democráticas va a la par con la debilidad del Congreso Nacional, tanto en su función legislativa como en su capacidad fiscalizadora de los actos del Ejecutivo. El presidencialismo exacerbado que instala la Constitución del 80, y que se mantiene e incluso se consolida durante los gobiernos de la Concertación, está lejos de favorecer la solidez de una representación política democrática canalizada

1. Una de las circunscripciones con senador designado -por su partido- es Valdivia, cuya ciudadanía, como ya vimos en la contienda electoral previa, no tuvo ningún poder decisorio, dado el acuerdo de las cúpulas partidistas de llevar candidatos protegidos, es decir, tantos candidatos como cupos a elegir. 
a través de partidos con poder parlamentario. Es que los partidos, en cuanto representantes del sentir ciudadano, tampoco han sido relevantes en la acción política del Ejecutivo durante los gobiernos de la Concertación, porque las decisiones fundamentales se han tomado en el secretismo, ya sea del segundo piso, donde actúan los asesores presidenciales de su exclusiva confianza, o del gabinete del Ministro del Interior, o bien, si se trata de políticas públicas, las decisiones han estado entregadas a los tecnócratas sectoriales del Ministerio de Hacienda. Encargados de velar por los equilibrios fiscales y evitar el gasto desfinanciado, estos terminaron por decidir sobre la definición de las políticas de todos los ministerios sociales, incluido, por cierto, el de educación. No nos sorprendamos entonces de la tremenda crisis en este sector, que ya lleva más de un lustro manifestándose.

Es evidente, dados todos estos condicionantes, que se ha generado una peligrosa crisis de representación. Peligrosa, por cierto, para el régimen democrático, entendiendo por tal la democracia representativa de matriz liberal con la que se gobierna Europa occidental desde la segunda postguerra, que es la que le permite superar los enormes traumas que dejara la destrucción bélica y los totalitarismos que la precipitaron.

Para el funcionamiento de la democracia, es fundamental que existan partidos políticos sólidos. Son estos los que canalizan y procesan la representación ciudadana, en la medida en que son las instancias que recogen las diversas y contradictorias demandas particulares o sectoriales, y las integran en una propuesta nacional, que a la vez es coherente y está guiada por un ideal de sociedad y una visión específica del futuro mediato de la sociedad donde se insertan. De allí la importancia de la dimensión doctrinaria o, si se prefiere, ideológica en la existencia de los partidos políticos. La misma pluralidad social en su interior les otorga esta capacidad de integrar demandas sectoriales en propuestas aplicables al conjunto de la sociedad, que es lo que caracteriza a los partidos políticos y los vuelve indispensables en un orden democrático.

Por cierto, no es la primera vez que se produce en la historia política chilena una crisis de representación y debilidad partidista. De hecho, de tales crisis surgieron nuevos sistemas de partidos en las décadas de 1930 y 1950. Puede que estemos en un escenario político semejante y presenciemos en un breve plazo una reformulación del sistema de partidos. Lo que no significa, por cierto, que desaparezcan los partidos actualmente vigentes, sino que estos tendrían que reformular sus propuestas políticas, es decir, su visión del futuro mediato de la sociedad chilena, a la luz de sus principios fundantes y sus ideales de sociedad; tendrían que estrechar nuevamente sus vínculos con la ciudadanía a la que representan, como una necesidad para no quedar fuera del juego político; y, como parte de este mismo proceso, habrán de redefinir sus alianzas partidistas. De modo que al reformularse el sistema de partidos tendrían que cambiar las combinaciones políticas, a la vez que deberían surgir nuevos partidos, algunos de los cuales llegarían a concitar considerable apoyo ciudadano, y tendrían que ser considerados por aquellos de más larga data en su política de alianzas.

La transformación del sistema de partidos se ha producido históricamente en un contexto de convulsión política, en el cual estos sufren de una crisis de representación, es decir, cuando la desafección de una ciudadanía que hasta entonces los había 
respaldado, ahora los obliga a reformularse, en algún sentido a recrearse. En la tercera década del siglo XX, la debilidad de los "partidos históricos" quedó en dramática evidencia al producirse la seguidilla de intervenciones militares, golpes de Estado y dictaduras que caracterizaron la política chilena entre 1924 y fines del 32. A comienzos de los años 30 surge un nuevo sistema de partidos cuando, por una parte, se crea el Partido Socialista, a la vez que el Partido Comunista decide implementar una nueva estrategia de alianzas, cubriendo al centro partidista, lo que culmina en la creación del Frente Popular en la segunda mitad de esa década; a la vez, los partidos Conservador y Liberal articulan entonces una alianza política de larga duración. A partir de esos procesos característicos de la primera mitad de la década de 1930 se puede comenzar a hablar con propiedad de izquierdas y derechas en la política chilena.

Con tal sistema partidista gobernaron los mandatarios provenientes del Partido Radical, hasta que veinte y tantos años más tarde, a comienzos de los años 50, el "terremoto ibañista" mostró a un electorado dispuesto a distanciarse de los partidos que lo habían representado hasta entonces, y presto a entregarle su respaldo a una figura autoritaria de tono populista, el "General de la Esperanza". Al menos por un tiempo, que fue breve gracias a la vitalidad y capacidad de recomposición que tuvieron los partidos al finalizar dicho gobierno. El nuevo sistema de partidos que surge al terminar esa década se caracteriza por la emergencia con gran poderío electoral del Partido Demócrata Cristiano, por la pérdida de la preeminencia que había tenido el Partido Radical desde los años 30, y por la redefinición de los partidos de izquierda y de su política de alianzas, fuertemente influidos por la Revolución cubana. El colapso de los partidos Liberal y Conservador a mediados de los años 60 y la creación de un solo partido de derecha vinieron a confirmar la polarización que asumía el sistema de partidos creado a fines de la década del 50.

El golpe de Estado de 1973 -lo sabemos- puso fin a toda forma de representación política, dejó a los partidos fuera de la ley y persiguió implacablemente a aquellos que habían integrado la Unidad Popular. Será, pues, en la segunda mitad de la década del 80 cuando se vuelve a configurar un nuevo sistema de partidos, a partir del entendimiento entre la Democracia Cristiana y el Partido Socialista, expresado en la Concertación de Partidos por la Democracia, alianza política de largo aliento bajo cuyo diseño estratégico se produce la transición democrática conducida a lo largo de cuatro períodos presidenciales. Habiéndose agotado este modelo veinte años después de su creación, es posible que ahora estemos a las puertas de su transformación.

Hay que notar que en las tres experiencias históricas reseñadas se visualizan elementos de continuidad con respecto al período anterior, especialmente en lo que se refiere a la persistencia de los partidos previamente vigentes, así como también de cambio, particularmente notorio en la transformación de los términos bajo los cuales se producen las alianzas partidistas, en el surgimiento de un nuevo partido, que se introduce en la arena política con el mismo peso que los que vienen de más atrás, y en una mayor participación política y electoral de la ciudadanía. En los años 80 se podría pensar que el nuevo partido en el escenario político es lo que se ha dado en llamar "el partido transversal", refiriéndose a un grupo homogéneo que domina los puestos decisivos del Ejecutivo, 
grupo cohesionado que tiene raíces tanto en el Partido Demócrata Cristiano como en el Partido Socialista, y en el que ejercen un rol hegemónico antiguos militantes de un partido católico-marxista minúsculo que integrara la Unidad Popular, es decir, el Mapu.

De alguna forma, el escenario político actual hace recordar a aquel de los años 50: Sebastián Piñera es un hombre ajeno a los partidos, los ha doblegado -en el caso de los que le han dado su apoyo electoral-, pero se nota que no confía en ellos; fue elegido apelando a sus atributos personales y a su condición de hombre de éxito en el mundo de los negocios e incluso -a pesar de ser el candidato de la derecha- en cuanto adversario de la dictadura pinochetista (un hombre que votó No en el plebiscito del 88); su primer gabinete fue integrado por independientes ajenos a los partidos que lo apoyaron en su campaña y le traspasaron sus votos. Al igual como ocurrió con el general Ibáñez, su gobierno ha perdido apoyo ciudadano muy rápidamente, a la vez que el desencanto se ha extendido también a los partidos de todo el espectro político, e incluso al Congreso Nacional. El escenario económico es muy diferente a aquel de los años 50, pero el contexto político se abre a las comparaciones.

En la actualidad, una reformulación del sistema de partidos y una nueva aproximación de estos con la ciudadanía, que permitiera recrear la representación política, requeriría urgentemente de una reforma electoral profunda, de modo tal que el electorado supiera que su voto tiene relevancia decisiva en el devenir de la política nacional. Ello implica por lo menos, a mi juicio, terminar de raíz con el régimen electoral binominal y con la designación de parlamentarios suplentes por parte de las dirigencias partidistas (las elecciones complementarias, por medio de las cuales se elegía al parlamentario que asumiría una vacancia en el Congreso, fueron parte fundamental de la historia política chilena, desde que se instituyeran en 1888 hasta la clausura de la vida política con el golpe de Estado de 1973). Por otra parte, la inscripción automática y el voto voluntario darían una señal de confianza de los partidos en la ciudadanía -confianza en esos votantes desconocidos y sorprendentes- y de sintonía con sus percepciones políticas, lo que tiene una enorme importancia por sí mismo.

Es presumible también que habrá que legislar sobre la vida interna de los partidos políticos, algo inédito en la historia chilena pero necesario para forzar la apertura de sus oligarquías que controlan la toma de decisiones y asegurar la creación de una razonable cercanía con sus bases sociales actuales y potenciales. Por cierto, a la vez habrá que forjar un espacio dentro del sistema representativo para los nuevos partidos que se vayan formando y decantando, de modo de que el nuevo sistema de partidos que se cree sea capaz de recibir las múltiples expresiones de una ciudadanía mucho más diversa que la que se representaba hace una veintena de años atrás.

Todo ello es deseable y necesario para fortalecer la democracia representativa, pero puede que nada de ello ocurra. En ese caso, tendremos caudillismo, populismo y representación corporativa.

En efecto, hoy en día es posible percibir intentos de legitimar e instalar la representación corporativa, intentos que apelan al progresismo, como siempre ha ocurrido, por lo demás, con las propuestas corporativistas. En esta perspectiva, se ha postulado el desiderátum de la representación ciudadana directa, queriendo decir con ello la 
instalación en el núcleo de la toma de decisiones políticas de una representación social que se expresa a través de organizaciones sectoriales (que asumen la representación de la totalidad del sector correspondiente), y sin la mediación de los partidos políticos. Aparentemente habría una mayor densidad democrática en el "mandato imperativo" que se les da a los representantes desde las organizaciones sociales. No obstante, este constituye un retroceso político, en la medida en que, como los representantes carecen de autonomía respecto de las asociaciones representadas, con este mandato imperativo se prescribe la posibilidad de negociación, de construcción de entendimientos mirando a la totalidad en una temporalidad más extensa que el presente inmediato. Aparentemente habría una mayor participación, incluso una participación directa en la toma de decisiones cuando los representantes de los sectores involucrados en un problema social, mandatados y sin autonomía, son consultados a través de instancias ad hoc. Pero ello más bien se trata de un mecanismo de control de la movilización social, incluso de utilización de una expansión controlada de la movilización social, generando una participación subordinada, dependiente, en un contexto populista. Se trata de una participación tan solo aparente, al igual que el mecanismo plebiscitario, en la medida en que toda decisión política implica conjugar un conjunto de intereses y demandas contradictorias, y procesarlas como tales. Por eso es que la prescindencia de los partidos políticos en su calidad de representantes de la ciudadanía en su conjunto y en su capacidad de articular decisiones en medio del conflicto de intereses, para ser reemplazados por representantes sectoriales, da solo una ilusoria sensación de participación.

La primera ocasión en que en los últimos tiempos ha ocurrido un ejercicio de representación corporativa ha sido con la creación del Consejo Asesor Presidencial para la Calidad de la Educación, convocado por el gobierno de Bachelet como respuesta a la protestas de estudiantes secundarios en 2006. En vez de someter el problema de la educación chilena, con sus múltiples aristas, a la consideración del conjunto de los partidos políticos para luego llevar la discusión al Congreso Nacional, Bachelet decidió diseñar un mecanismo para la toma de decisiones que institucionalizaba la consulta directa a los actores involucrados en el problema. Así, en forma personalista y centralizada, definió la composición de quienes debían conformar este Consejo Asesor Presidencial de donde habrían de salir las nuevas políticas de educación. Así, dicha asamblea estuvo integrada por representantes de cada sector interesado, fuesen de organizaciones de estudiantes universitarios y de secundarios, rectores universitarios, directivos del Colegio de Profesores, representantes de los dueños de colegios particulares subvencionados, de los alcaldes, etc., además de un puñado de autodefinidos expertos en la materia. Por cierto, de tal conjunto no podría salir una propuesta que recogiera todas las demandas y visiones contrapuestas, y que permitiera a la vez que todos estuviesen satisfechos, como se esperaba. En la redacción final se impusieron los "expertos" más audaces, mientras que aquellos sectores con mayores quejas y demandas - por de pronto los estudiantes secundarios- se sintieron engañados, y el Ejecutivo tuvo que someter la discusión del problema educacional a la consideración de los partidos políticos antes de poder enviar algún proyecto de ley al Congreso Nacional. Al final de cuentas, lo que se logró con el modelo del Consejo Asesor fue desmovilizar por 
algún tiempo a los estudiantes, profundizar el sentimiento contrario a los partidos políticos y al Congreso Nacional, y poner en práctica una experiencia de representación corporativa.

El corporativismo es un modelo político de vieja data en América Latina, propugnado tanto por sectores de derecha como de izquierda, incluyendo por cierto a las corrientes socialcristianas. En los años 30 tuvo su momento de mayor auge en el pensamiento político chileno. Desde una perspectiva de izquierdas se propuso entonces un corporativismo-socialista, en un Estado funcional, con un federalismo funcional, construido desde la base social, sindical y de productores, desestimando la intermediación de los partidos políticos en la representación ciudadana y en la articulación de intereses contradictorios. También se propugnó crear una Constitución funcional, es decir, con representación corporativa-sindical. Tengo la impresión que algunas de estas mismas ideas hemos comenzado a escuchar en los discursos de universitarios, sea de profesores o de alumnos, en los últimos años.

Si bien en sus expresiones más difusas el corporativismo ha podido convivir con sistemas democráticos, suele ir acompañando al caudillismo autoritario, ciertamente antiparlamentario. El líder caudillista podrá buscar su legitimidad tanto a través de formas de representación corporativa en un Estado centralizador, representación fácil de manipular, como a través del recurso plebiscitario utilizado en caso de que haya mucha controversia social respecto a un tema específico. A fin de cuentas, el modelo corporativo pone fin al pluralismo político, moviliza a los sectores sociales pero a la larga solo en apoyo a los gobernantes, y debilita o pone fin a los partidos políticos como canales de representación ciudadana, y también al Congreso Nacional como el espacio político por excelencia para la negociación y el acuerdo en una sociedad plural. Ante la persistente presencia de caudillismos en América Latina, últimamente de izquierda, es conveniente tener presente cuáles caminos conducen al corporativismo caudillista, sabiendo por experiencia histórica cuán difícil es recuperar el pluralismo político en las sociedades de la América Latina.

\section{REFEREENCIAS BIBLIOGRÁFICAS}

Barómetro de la política, mayo-junio 2011, online en: http://www.cerc.cl/pdf/Barómetro_de_la_ política.pdf, [consulta: 24 de julio de 2011].

Bellei, Cristián; Contreras, Daniel y Valenzuela, Juan Pablo, eds., Ecos de la Revolución Pingüina. Avances, debates y silencios en la reforma educacional. Santiago: Pehuén Editores, 2010.

Correa, S., "El corporativismo como expresión política del socialcristianismo", en Teología y Vida. xlix (3), $3^{\circ}$ trimestre 2008, págs. 467-481.

Correa, S., Con las riendas del poder. La derecha chilena en el siglo XX, $2^{a}$ ed., Santiago: Debolsillo, 2011.

Correa, Sofía y Ruiz-Tagle Vial, P., Ciudadanos en Democracia. Fundamentos del sistema político chileno, Santiago: Debate, 2010.

Correa, Sofía; Figueroa, Consuelo; Jocelyn-Holt, Alfredo; Rolle, Claudio y Vicuña, Manuel, Historia del siglo XX chileno. Balance Paradojal, Santiago: Editorial Sudamericana, 2001. 
Cotta, M., "Representación Política", en Diccionario de política, bajo la dirección de Norberto Bobbio, Nicola Matteucci y Gianfranco Pasquino, 10 $10^{a}$ ed. en español, Madrid: Siglo XXI Editores, 1997, tomo 2, págs. 1384-1390.

Drake, Paul W., "Corporatism and Functionalism in Modern Chilean Politics", en Journal of Latin American Studies, 10 (1), mayo 1978, págs. 83-116.

Encuesta: Evaluación Gestión del Gobierno, Informe Mensual Junio 2011. Adimark, GFK, online en: http://www.adimark.cl/es/estudios/documentos/06_ev_gob_jun_02011.pdf, [consulta 24 de julio de 2011]

Entrevista a Alfredo Jocelyn-Holt, partes 1-4, subida el 23 de julio de 2011, online en: http:// elpost.cl/, [consulta 24 de julio de 2011]

Incisa, L., "Corporativismo", en Diccionario de política, bajo la dirección de Norberto Bobbio, Nicola Matteucci y Gianfranco Pasquino, $10^{\mathrm{a}}$ ed. en español, Madrid: Siglo XXI Editores, 1997, tomo 1, págs. 372-377.

Jocelyn-Holt, A., El Chile Perplejo. Del avanzar sin transar al transar sin parar, Santiago: Planeta/ Ariel, 1998.

Kaufman, Robert R., "Corporatism, Clientelism, and Partisan Conflict: A study of seven Latin American countries", en Malloy, James M. (Ed.), Authoritarianism and Corporatism in Latin America, $2^{a}$ ed., Pittsburg: University of Pittsburg Press, 1979, págs. 109-148.

Oppo, A., "Partidos Políticos", en Diccionario de politica, bajo la dirección de Norberto Bobbio, Nicola Matteucci y Gianfranco Pasquino, $10^{\text {a }}$ ed. en español, Madrid: Siglo XXI Editores, 1997, tomo 2, págs. 1153-1160.

Schmitter, Philippe C., "Still the Century of Corporatism?", en Pike, Fredrick B. y Stritch, Thomas (Eds.), The New Corporatism. Social Political Structures in the Iberian World, Notre Dame, Londres: University of Notre Dame Press, 1974, págs. 85-131. 